\title{
Preoperative SCC-Ag as a predictive marker for the use of adjuvant chemotherapy in cervical squamous cell carcinoma with intermediate-risk factors
}

Hong-tao Guo

Lanzhou University

\section{Xue-han Bi}

Lanzhou University

Ting Lei

Lanzhou University

Xiao Lv

Lanzhou University

Guang Yao

Lanzhou University

Yao Chen

Lanzhou University

Chang Liu ( $\nabla$ chliumd@163.com )

The First Hospital of Lanzhou University

\section{Research article}

Keywords: cervical cancer, chemotherapy, radiotherapy, squamous cell carcinoma

Posted Date: January 14th, 2020

DOI: https://doi.org/10.21203/rs.2.20782/v1

License: (c) (i) This work is licensed under a Creative Commons Attribution 4.0 International License. Read Full License

Version of Record: A version of this preprint was published at BMC Cancer on May 19th, 2020. See the published version at https://doi.org/10.1186/s12885-020-06928-9. 


\section{Abstract}

\section{Background}

For cervical cancer patients whose tumors display a combination of intermediate risk factors, postoperative radiation with or without adjuvant chemotherapy is suggested for them. However, who should be administered with adjuvant chemotherapy is unknown. The current study was designed to explore the clinical value of squamous cell carcinoma antigen in guiding the use of adjuvant chemotherapy in cervical cancer patients.

\section{Methods}

A retrospective study of 301 cervical cancer patients treated by surgery and adjuvant treatment from Mar. 2005 to Mar. 2015 was performed. All patients were divided into two groups according to receiving adjuvant chemotherapy or not. Overall survival (OS), disease-free survival (DFS) were compare between patients who did and did not receive adjuvant radiotherapy. Multivariate analysis was employed to detect clinical factors associated with disease-free survival, local recurrence-free survival and distant metastasis-free survival.

\section{Results}

For patients with high pre-treatment squamous cell carcinoma level, DFS and OS in adjuvant chemoradiotherapy group were higher than that in adjuvant radiotherapy group. Besides, the rates of distant metastasis were found lower in patients who did receive adjuvant chemotherapy than those who did not. For patients with upper low pre-treatment squamous cell carcinoma level, the 5-year OS and DFS were similar between groups of adjuvant chemo-radiotherapy and adjuvant radiotherapy. Multivariable analysis indicated adjuvant chemotherapy was independent predictors of DFS and distant metastasisfree survival in patients with high squamous cell carcinoma level.

\section{Conclusion}

Squamous cell carcinoma can serve as an indication for the administration of adjuvant chemotherapy in cervical cancer patients.

\section{Background}

As we know, cervical cancer is the one of the most common cancer in women worldwide [1]. The standard treatment for early-stage cervical cancer is surgery. However, adjuvant chemo-radiotherapy plays still an important role in the integrated therapy when some pathological findings are found after surgery. The common factors such as lymph node metastasis, parametrial involvement and positive surgical margin are known as "high-risk" factors and patients with any of these features are suggested to receive postoperative concurrent chemo-radiotherapy [2]. But, for patients whose tumors present with a combination of intermediate risk factors such as large size, deep stromal invasion, and lymphovascular 
involvement, postoperative pelvic radiation is suggested for them with no mandatory need of adjuvant chemotherapy [3]. Thus, the problem is that who should be given with adjuvant chemotherapy is still unknown for the patients with two intermediate-risk factors. Moreover, there is also no consensus reached by physicians on this topic, leading to over or less treatment for some patients with intermediate-risk factors.

Squamous cell carcinoma antigen (SCC), which is produced through squamous formation of cervical squamous epithelium, is a biomarker routinely used in clinical practice [4]. Approximately $28-88 \%$ of cervical squamous cell carcinomas were with abnormal level of serum squamous cell carcinoma level, which is very meaningful in cervical cancer patients [5]. Many studies found that pre-treatment squamous cell carcinoma could predict disease progression after treatments [6-10]. Besides, squamous cell carcinoma level was also employed to evaluate the response to treatment [11]. However, whether preoperative squamous cell carcinoma antigen can be a predictive marker for the use of adjuvant chemotherapy in cervical squamous cell carcinoma is still unknown. In our present study, we tried to identify the clinical value of squamous cell carcinoma antigen in the administration of adjuvant chemotherapy in early stage cervical cancer with intermediate-risk factors.

\section{Methods}

\section{Ethics Statement}

This research was approved by the First Hospital of Lanzhou University, and written informed consent was obtained from every patient included in the study.

\section{Patients and procedures}

We acquired our data from a database at First Hospital of Lanzhou University from Mar. 2006 to Mar. 2016. The selection criteria for the current study were as follows: (1) pathologically confirmed uterine cervical cancer with two intermediate-risk factors; (2) received surgery followed by adjuvant radiotherapy or adjuvant chemo-radiotherapy; (3) the function of liver and renal function is normal; (4) no concurrent cancer and (5)did not receive radiotherapy to the pelvis previously. Patients with any high-risk factors were excluded. After careful reviewing the patients' information, 301 patients met the inclusion criteria and were analyzed in the present study.

\section{Clinical Evaluation}

We performed the clinical staging with the help of physical examination, computed tomography or magnetic resonance imaging, and chest radiography. Besides, complete blood count and liver function test were also performed. Pre-treatment squamous cell carcinoma levels were measured within 2 weeks before surgery. The median level of SCC for the whole group of patients was $6.09 \mathrm{ng} / \mathrm{ml}$. And we adopted the median level of SCC to divide all the patients into two groups: high squamous cell carcinoma level group $(>6.09 \mathrm{ng} / \mathrm{ml})$ and low squamous cell carcinoma level group $(\leq 6.09 \mathrm{ng} / \mathrm{ml})$. 


\section{Chemotherapy}

Part of the patients received adjuvant chemotherapy. The regimen usually contained $5-\mathrm{Fu}\left(3-4 \mathrm{~g} / \mathrm{m}^{2}\right.$, civ96h) and cisplatin $\left(70 \mathrm{mg} / \mathrm{m}^{2}\right)$ and it was given to the patients every 3 weeks. Besides, other regimen including paclitaxel plus cisplatin was also used. And the details of this regimen are as follows: paclitaxel $135 \mathrm{mg} / \mathrm{m}^{2}$ and cisplatin $70 \mathrm{mg} / \mathrm{m}^{2}$. The median cycles of adjuvant chemotherapy were 3(2-4). Usually, two cycles of adjuvant chemotherapy were concurrent with postoperative radiotherapy.

\section{Radiotherapy}

Patients were suggested to receive postoperative radiation. The prescribed dose for the whole pelvis was 45-50 Gy/23-25F. And it was performed for 5 days per week with a total treatment duration of 5-6 weeks. As for the details of radiotherapy, the clinical target volume (CTV) included the primary tumor bed, paracervical tissue, supra-vaginal portion, common iliac lymph nodes, internal and external iliac lymph nodes, obturator lymph nodes, and sacral lymph nodes. The superior border of the CTV was the bottom of L4, and the inferior border was the lower margin of the obturator. The anterior border was the posterior margin of the bladder and the posterior border was the anterior margin of the sacrum.

\section{Follow-up evaluation}

The patients were followed up every 3 months for the first 2 years and every 6 months during the following 3 years. After 5 years, they were suggested to visit their physician annually. Routine evaluations include complete blood cell counts, SCC, biochemical routines and physical examinations. Chest radiography and computed tomography or magnetic resonance imaging of the abdomen and pelvis were performed every 6 months. Disease-free survival and overall survival were defined from the date of diagnosis to the date of recurrence or metastasis and to the date of death, respectively. And for surviving patients, they were defined to the date of the last follow-up.

\section{Statistical analysis}

The statistical analyses were done by using SPSS software, version 20.0. Categorical variables were analyzed using the chi-square test or Fisher's exact test. Continuous variables were analyzed using the Student's $t$ test or the Mann-Whitney $U$ test. The comparisons of disease-free survival and overall survival rates between different group were performed by using Kaplan-Meier method. Multivariate analysis of disease-free survival, local recurrence-free survival and distant metastasis-free survival was analyzed using Cox proportional hazards regression. $p<0.05$ was considered to be statistically significant.

\section{Results}

\section{Clinical Characteristics}


In all, we enrolled 301 cervical cancer patients who were with two intermediate risk factors. Among them, 156 patents received adjuvant chemo-radiotherapy, while the rest of 145 patents received adjuvant radiotherapy alone. Compared to patients who received adjuvant radiotherapy alone, those who received chemo-radiotherapy presented no difference in clinical tumor stage, tumor size, lympho-vascular involvement, deep stromal invasion and follow-up. However, patients who did receive adjuvant concurrent chemotherapy tend to be younger than those who did not (Table 1). 
Table 1

Patient Demographics and Baseline Tumor Characteristics

\begin{tabular}{|c|c|c|c|}
\hline Variable & $\begin{array}{l}\text { Adjuvant chemo-radiotherapy }(n= \\
156)\end{array}$ & $\begin{array}{l}\text { Adjuvant radiotherapy }(n= \\
145)\end{array}$ & $\begin{array}{l}\mathrm{p} \\
\text { value }\end{array}$ \\
\hline Age, year & & & 0.046 \\
\hline median & 60 & 63 & \\
\hline Stage & & & 0.752 \\
\hline $\mathrm{IA} 2$ & 4 & 5 & \\
\hline IB1 & 88 & 82 & \\
\hline IB2 & 11 & 13 & \\
\hline IIA1 & 36 & 35 & \\
\hline IIA2 & 17 & 10 & \\
\hline LVSI & & & 0.562 \\
\hline yes & 66 & 67 & \\
\hline no & 90 & 78 & \\
\hline DSI & & & 1.000 \\
\hline yes & 132 & 122 & \\
\hline no & 24 & 23 & \\
\hline Tumor size & & & 0.526 \\
\hline$\geq 4$ & 114 & 101 & \\
\hline$<4$ & 42 & 44 & \\
\hline Risk group & & & 0.787 \\
\hline $\begin{array}{l}\text { large Tumor + } \\
\text { DSI }\end{array}$ & 90 & 78 & \\
\hline $\begin{array}{l}\text { large Tumor + } \\
\text { LVSI }\end{array}$ & 24 & 23 & \\
\hline DSI + LVSI & 42 & 44 & \\
\hline $\begin{array}{l}\text { Follow up, } \\
\text { months }\end{array}$ & & & 0.932 \\
\hline
\end{tabular}

Abbreviation: DSI, deep stromal invasion; LVSI, lymph-vascular space invasion; SCC, squamous cell carcinoma; 


\begin{tabular}{|llll|}
\hline Variable & $\begin{array}{l}\text { Adjuvant chemo-radiotherapy }(\mathbf{n}= \\
\text { 156) }\end{array}$ & $\begin{array}{l}\text { Adjuvant radiotherapy }(\mathbf{n}= \\
145)\end{array}$ & $\begin{array}{l}\mathbf{p} \\
\text { value }\end{array}$ \\
\hline median & 56.9 & 56.6 \\
\hline $\begin{array}{l}\text { Abbreviation: DSI, deep stromal invasion; LVSI, lymph-vascular space invasion; SCC, squamous cell } \\
\text { carcinoma; }\end{array}$
\end{tabular}

\section{Survival Analysis for the whole group}

During the follow up, for the whole group, there were 40 patients who died. The 5-year overall survival in the adjuvant chemo-radiotherapy and adjuvant radiotherapy groups were $90.29 \%$ and $81.29 \%$, respectively (Fig. 1, Table 2). No significant difference was showed in overall survival between the two groups Fifty-six patients suffered recurrence, of them, local recurrence was found in 13 patients, distant metastasis was showed in 28 patients and 15 patients were with both local and distant recurrences. The common metastatic sites were liver, lung, bone and lymph nodes. Compared to patients who did not received adjuvant chemotherapy, those who did acquired better disease-free survival $(86.11 \%$ vs $74.89 \%$, $\mathrm{p}=0.004)(($ Fig. 2, Table 2).

Table 2

Survival for the Whole Group Patients

\begin{tabular}{|llllll|}
\hline \multirow{2}{*}{ Group } & \multicolumn{2}{l}{ Adjuvant chemo-radiotherapy $(\mathbf{n = 1 5 6 )}$} & \multicolumn{2}{l}{ Adjuvant radiotherapy $(\mathbf{n = 1 4 5 )}$} & P value \\
\cline { 2 - 5 } & 3-year & 5-year & 3-year & 5-year & \\
\hline OS & $96.15 \%$ & $90.29 \%$ & $91.02 \%$ & $81.29 \%$ & 0.060 \\
\hline DFS & $91.59 \%$ & $86.11 \%$ & $80.67 \%$ & $74.89 \%$ & 0.004 \\
\hline Abbreviations: OS = overall survival; DFS = disease-free survival. & & \\
\hline \#: calculated by Kaplan-Meier method & & & \\
\hline
\end{tabular}

\section{Survival Analysis for Patients with high Squamous Cell Carcinoma level}

For patients with high squamous cell carcinoma level, there were 25 cases who died and there were 33 patients who developed recurrence. Nine patients were with local recurrence alone and 13 patients suffered from only distant metastasis. Additionally, 11 patients presented with both local and distant metastasis. Patients in the adjuvant chemo-radiotherapy group acquired better 5 -year overall survival $(87.8 \%$ vs $88.4 \%, p=0.802)$ and disease-free survival $(76.9 \%$ vs $80.4 \%, p=0.556)$ than those in the adjuvant radiotherapy group (Figs. 3 and 4 , Table 3 ). We also analyze the recurrence pattern, with result showing that there was no difference in local recurrence between groups with radiotherapy and chemradiotherapy. However, distant metastasis was significantly higher in the radiotherapy group than that in the chemo-radiotherapy group $(p=0.036)($ Table 4$)$. 
Table 3

Survival for the Patients with high SCC level

\begin{tabular}{|llclll|}
\hline \multirow{2}{*}{ Group } & \multicolumn{2}{l}{ Adjuvant chemo-radiotherapy $(\mathbf{n = 8 4})$} & \multicolumn{2}{l}{ Adjuvant radiotherapy $(\mathbf{n = 6 7 )}$} & \multirow{2}{*}{ p value } \\
\cline { 2 - 4 } & 3-year & 5-year & 3-year & 5-year & \\
\hline OS & $94.05 \%$ & $90.72 \%$ & $86.57 \%$ & $73.41 \%$ & 0.015 \\
\hline DFS & $89.16 \%$ & $86.03 \%$ & $77.61 \%$ & $69.40 \%$ & 0.007 \\
\hline Abbreviations: OS = overall survival; DFS = disease-free survival. & & \\
\hline
\end{tabular}

Table 4

Recurrence Patterns for Patients with high SCC level

\begin{tabular}{|llllll|}
\hline \multirow{2}{*}{ Group } & \multicolumn{2}{l}{ Adjuvant chemo-radiotherapy $(\mathbf{n = 8 4})$} & \multicolumn{2}{l}{ Adjuvant radiotherapy $(\mathbf{n = 6 7 )}$} & \multirow{2}{*}{ p value } \\
\cline { 2 - 4 } & 3-year & 5-year & 3-year & 5-year & \\
\hline LR & $5(6.0 \%)$ & $7(8.3 \%)$ & $8(11.9 \%)$ & $10(14.9 \%)$ & 0.069 \\
\hline SM & $5(6.0 \%)$ & $6(7.1 \%)$ & 11(16.4\%) & 18(26.9\%) & 0.002 \\
\hline Abbreviations: LR = local recurrence; SM = systemic metastases & & \\
\hline \#: calculated by Kaplan-Meier method & & & \\
\hline
\end{tabular}

\section{Survival Analysis for Patients with low Squamous Cell Carcinoma level}

For patients with low squamous cell carcinoma level, 23 patients recurred with 15 patents dying of tumor recurrence. Four patients recurred only locally, 15 patients had only distant metastasis and 4 patients developed both local and distant recurrences. The 5-year overall survival and disease-free survival in the adjuvant chemo-radiotherapy and adjuvant radiotherapy groups were $90.65 \%, 86.62 \%$ and $88.74 \%$, $79.63 \%$, respectively (Figs. 5 and 6, Table 5). No significant differences were found in both overall survival $(p=0.097)$ and disease-free survival $(p=0.253)$. Further analysis of recurrence pattern, results just showed that there were no differences in both the local and distant failure between patients did and did not receive adjuvant chemotherapy (Table 6). 
Table 5

Survival for the Patients with low SCC level

\begin{tabular}{|llclll|}
\hline \multirow{2}{*}{ Group } & \multicolumn{2}{l}{ Adjuvant chemo-radiotherapy $(\mathbf{n = 7 2 )}$} & \multicolumn{2}{l}{ Adjuvant radiotherapy $(\mathbf{n = 7 8 )}$} & \multirow{2}{*}{ p value } \\
\cline { 2 - 4 } & 3-year & 5-year & 3-year & 5-year & \\
\hline OS & $98.61 \%$ & $90.65 \%$ & $94.84 \%$ & $88.74 \%$ & 0.791 \\
\hline DFS & $94.36 \%$ & $86.62 \%$ & $83.27 \%$ & $79.63 \%$ & 0.146 \\
\hline Abbreviations: OS = overall survival; DFS = disease-free survival. & & \\
\hline \#: calculated by Kaplan-Meier method & & & \\
\hline
\end{tabular}

Table 6

Recurrence Patterns for Patients with low SCC level

\begin{tabular}{|c|c|c|c|c|c|}
\hline \multirow[t]{2}{*}{ Group } & \multicolumn{2}{|c|}{ Adjuvant chemo-radiotherapy $(n=72)$} & \multicolumn{2}{|c|}{ Adjuvant Radiotherapy $(n=78)$} & \multirow[t]{2}{*}{$\mathrm{p}$ value } \\
\hline & 3-year & 5-year & 3-year & 5-year & \\
\hline LR & $1(1.4 \%)$ & $3(4.2 \%)$ & $2(2.6 \%)$ & $5(6.4 \%)$ & 0.612 \\
\hline SM & $3(4.2 \%)$ & $8(11.1 \%)$ & $10(12.8 \%)$ & $11(14.1 \%)$ & 0.515 \\
\hline \multicolumn{6}{|c|}{ Abbreviations: $\mathrm{LR}=$ local recurrence; $\mathrm{SM}=$ systemic metastases } \\
\hline \#: calcu & ted by $\mathrm{K}$ & method & & & \\
\hline
\end{tabular}

Clinical predictors for disease-free survival, local recurrence-free survival and distant metastasis-free survival for patients with high Squamous Cell Carcinoma level

For patients with high squamous cell carcinoma level, results showed that tumor size and deep stromal invasion were independent predictors of disease-free survival and distant metastasis-free survival. Besides, adjuvant chemotherapy was found to be the unique factor significantly associated with distant metastasis-free survival, indicating that patients who received adjuvant chemotherapy suffered less distant failure than those who did not (Table 7). 
Table 7

Multivariate Analyses of DFS, LRFS, and DMFS for Patients with high SCC level

\begin{tabular}{|c|c|c|c|c|c|c|}
\hline \multirow[t]{2}{*}{ Variable } & \multicolumn{2}{|l|}{ DFS } & \multicolumn{2}{|l|}{ LRFS } & \multicolumn{2}{|l|}{ DMFS } \\
\hline & HR $(95 \% \mathrm{Cl})$ & $\begin{array}{l}\mathrm{P} \\
\text { value }\end{array}$ & $\mathrm{HR}(95 \% \mathrm{Cl})$ & $\begin{array}{l}p \\
\text { value }\end{array}$ & $\mathrm{HR}(95 \% \mathrm{Cl})$ & $\begin{array}{l}p \\
\text { value }\end{array}$ \\
\hline $\begin{array}{l}\text { Adjuvant } \\
\text { chemotherapy } \\
\text { Yes vs no }\end{array}$ & $\begin{array}{l}0.456(0.217- \\
0.957)\end{array}$ & 0.038 & $\begin{array}{l}0.538(0.207- \\
1.401)\end{array}$ & 0.204 & $\begin{array}{l}0.282(0.111- \\
0.721)\end{array}$ & 0.008 \\
\hline $\begin{array}{l}\text { Tumor size } \\
\geq 4 \mathrm{~cm} \text { vs }<4 \mathrm{~cm}\end{array}$ & $\begin{array}{l}2.988(1.278- \\
6.984)\end{array}$ & 0.012 & $\begin{array}{l}3.213(1.426- \\
7.335)\end{array}$ & 0.007 & $\begin{array}{l}1.731(0.701- \\
4.276)\end{array}$ & 0.234 \\
\hline $\begin{array}{l}\text { DSI } \\
\text { Yes vs no }\end{array}$ & $\begin{array}{l}2.083(0.988- \\
4.391)\end{array}$ & 0.054 & $\begin{array}{l}2.886(1.012- \\
8.235)\end{array}$ & 0.048 & $\begin{array}{l}1.410(0.603- \\
3.296)\end{array}$ & 0.428 \\
\hline $\begin{array}{l}\text { LVSI } \\
\text { No vs yes }\end{array}$ & $\begin{array}{l}0.645(0.319- \\
1.302)\end{array}$ & 0.221 & $\begin{array}{l}0.610(0.241- \\
1.541)\end{array}$ & 0.296 & $\begin{array}{l}0.658(0.288- \\
1.501)\end{array}$ & 0.319 \\
\hline
\end{tabular}

\section{Discussion}

Our current study demonstrated that, for patients with intermediate-risk factors, those who received adjuvant chemotherapy acquired better disease-free survival than those who did not, although no significant differences was found in overall survival. Based on the pre-treatment squamous cell carcinoma level, we further performed subgroup analysis with results showing that adjuvant chemotherapy was clinically meaningful only in patients with elevated squamous cell carcinoma level by improving both the DFS and OS. However, in patients with low squamous cell carcinoma level, adjuvant concurrent chemotherapy seemed to contribute little in improving the survival in this subgroup. Additional multivariable analysis further confirmed that adjuvant concurrent chemotherapy was independent prognostic factor for disease-free survival, local recurrence-free survival and distant metastasis-free survival in cervical cancer patients with elevated squamous cell carcinoma level.

In the present study, we found that preoperative squamous cell carcinoma could act as a predictive marker for the use of adjuvant chemotherapy in cervical squamous cell carcinoma with intermediate-risk factors. Besides, increased pretreatment squamous cell carcinoma levels was also a strong predictor of poor survival in cervical cancer patients and it has been widely used to predict the tumor recurrence after treatment $[10,12,13]$. In the study of Huang, et al, 188 patients with squamous cell carcinoma of the uterine cervix were retrospectively analyzed, with results showing that both squamous cell carcinoma levels $\geq 40 \mathrm{ng} / \mathrm{mL}(p<0.001)$ and squamous cell carcinoma levels of $10-40 \mathrm{ng} / \mathrm{mL}(p<0.001)$ were significant factors for para-aortic lymph node recurrence. And the corresponding 5-year para-aortic lymph node recurrence rates were $84.8 \%$, and $27.5 \%$, respectively, which just indicated that higher level of 
squamous cell carcinoma antigen caused higher rate of para-aortic lymph node recurrence [6]. In another study performed by Liu et al, one hundred ninety-seven cervical cancer patients who had received curative treatment with FIGO stage IB1 were included. Their data revealed that, among squamous cell carcinoma histology, patients with an $\mathrm{Hb}$ level less than $12 \mathrm{~g} / \mathrm{dl}$ and a squamous cell carcinoma level more than $3 \mathrm{ng} / \mathrm{ml}$ had worse oncologic outcomes [8]. Besides, some studies showed that elevated levels of squamous cell carcinoma were significantly associated with lymph node metastasis, which was a major risk factor of impaired survival in cervical cancer patients [14]. But, the reported cut-off values of squamous cell carcinoma level in predicting lymph node metastasis differed among the studies [15-17].

For patients with intermediate-risk factors who received adjuvant postoperative radiotherapy, the main treatment failure was distant metastasis [18]. This may be the possible reason of that adjuvant radiotherapy could only decrease local-regional recurrence, but failed to improve overall survival [19]. Adjuvant chemotherapy could decrease the rate of distant metastasis, thus the addition of chemotherapy to the treatment may be reasonable for cervical cancer patients after surgery. And it have been reported that adjuvant chemotherapy was effective in early stage cervical cancer with surgically confirmed intermediate risk factors [20] However, few studies has directly compared the efficacy between adjuvant chemo-radiotherapy and adjuvant radiotherapy in cervical cancer with intermediate risk factors. We found that squamous cell carcinoma antigen can be used to guide the adjuvant concurrent chemotherapy. In details, for patients with high pre-treatment squamous cell carcinoma level, adjuvant therapy should be administered to them due to the improvement in survival. while, in patients with low squamous cell carcinoma antigen level, adjuvant chemotherapy failed to improve the oncologic outcome. As we know, this new finding was the first to be reported and we suggested a novel clinical use of squamous cell carcinoma antigen. Besides, we also found that tumor size and deep stromal invasion were independent predictors of disease-free survival and distant metastasis-free survival, which was in consistent with other study [21]. Our multivariate analysis showed that adjuvant chemotherapy was significantly associated with distant metastasis-free survival, indicating that patients who received adjuvant chemotherapy suffered less distant failure than those who did not. Based on the related discussion above, the possible explanation for our new finding were as follows: 1. high pre-treatment SCC level predicted high rates of recurrence and adjuvant chemotherapy was effective in cervical cancer patients with intermediate-risk factors; 2 . Due to the poor survival in patients with high squamous cell carcinoma level, adjuvant chemotherapy could significantly improve the oncologic outcome. However, in patients with low squamous cell carcinoma level, the survival improvement brought by adjuvant chemotherapy may be little and not clinically significant because of the relatively favorable oncologic outcome in these patients who undergone adjuvant radiotherapy alone.

Some limitations were with our study. First, the selection bias could not be avoided because of the retrospective design of our study. But we found that most of the clinical variables were balanced between patients who did and did not have an elevated squamous cell carcinoma level. Secondly, the sample size in our work is relatively small. One of the reasons was that we only selected the patients with intermediate-risk factors, not including those with high-risk or no-risk factors. Besides, we chose the median pre-treatment level of squamous cell carcinoma to divide all the patients into two group, which 
was based on the method adopted in other studies [22, 23]. Perhaps, a better cut-off value of squamous cell carcinoma antigen may be achieved by receiver operating characteristic curve method. And that is work we will be done in the future.

In conclusion, pre-treatment squamous cell carcinoma antigen can be a predictive marker for the use of adjuvant chemotherapy in cervical squamous cell carcinoma with intermediate-risk factors. However, further larger-scale cohort studies are still warranted to prove this finding.

\section{Declarations}

\section{Ethics approval and consent to participate}

This research was approved by the First Hospital of Lanzhou University, and written informed consent was obtained from every patient included in the study.

\section{Consent for publication}

Not applicable

\section{Availability of data and materials}

The datasets used and/or analyzed during the current study are available from the corresponding author on reasonable request.

\section{Competing interests}

The authors have no potential conflicts of interest to disclose.

\section{Funding}

No funding.

\section{Authors' contributions}

GHT conceived the study and wrote the manuscript. BXH and LT participated in the clinical data collection. LX and YG modified the figures. CY performed the statistical analysis. LC and GHT supervised and helped study design and participated in its design and final approval of the version to be published. All authors read and approved the final manuscript.

\section{Acknowledgements}

No acknowledgements.

\section{References}


1. Torre LA, Siegel RL, Ward EM, Jemal A. Global Cancer Incidence and Mortality Rates and Trends--An Update. Cancer epidemiology, biomarkers \& prevention : a publication of the American Association for Cancer Research, cosponsored by the American Society of Preventive Oncology. 2016, 25(1):1627.

2. Peters WA, 3rd, Liu PY, Barrett RJ, 2nd, Stock RJ, Monk BJ, Berek JS, et al. Concurrent chemotherapy and pelvic radiation therapy compared with pelvic radiation therapy alone as adjuvant therapy after radical surgery in high-risk early-stage cancer of the cervix. Journal of clinical oncology : official journal of the American Society of Clinical Oncology. 2000, 18(8):1606-1613.

3. Rotman M, Sedlis A, Piedmonte MR, Bundy B, Lentz SS, Muderspach LI, et al. A phase III randomized trial of postoperative pelvic irradiation in Stage IB cervical carcinoma with poor prognostic features: follow-up of a gynecologic oncology group study. International journal of radiation oncology, biology, physics. 2006, 65(1):169-176.

4. Maruo T, Yoshida S, Samoto T, Tateiwa Y, Peng X, Takeuchi S, et al. Factors regulating SCC antigen expression in squamous cell carcinoma of the uterine cervix. Tumour biology : the journal of the International Society for Oncodevelopmental Biology and Medicine. 1998, 19(6):494-504.

5. Ohara K, Tanaka Y, Tsunoda H, Nishida M, Sugahara S, Itai Y. Assessment of cervical cancer radioresponse by serum squamous cell carcinoma antigen and magnetic resonance imaging. Obstetrics and gynecology. 2002, 100(4):781-787.

6. Huang EY, Huang YJ, Chanchien CC, Lin H, Wang CJ, Sun LM, et al. Pretreatment carcinoembryonic antigen level is a risk factor for para-aortic lymph node recurrence in addition to squamous cell carcinoma antigen following definitive concurrent chemoradiotherapy for squamous cell carcinoma of the uterine cervix. Radiation oncology (London, England). 2012, 7:13.

7. Reesink-Peters N, van der Velden J, Ten Hoor KA, Boezen HM, de Vries EG, Schilthuis MS, et al. Preoperative serum squamous cell carcinoma antigen levels in clinical decision making for patients with early-stage cervical cancer. Journal of clinical oncology : official journal of the American Society of Clinical Oncology. 2005, 23(7):1455-1462.

8. Liu SC, Huang EY, Hu CF, Ou YC, ChangChien CC, Wang CJ, et al. Pretreatment Factors Associated with Recurrence for Patients with Cervical Cancer International Federation of Gynecology and Obstetrics Stage IB1 Disease. Gynecologic and obstetric investigation. 2016, 81(4):339-345.

9. Jeong BK, Huh SJ, Choi DH, Park W, Bae DS, Kim BG. Prognostic value of different patterns of squamous cell carcinoma antigen level for the recurrent cervical cancer. Cancer research and treatment : official journal of Korean Cancer Association. 2013, 45(1):48-54.

10. Shimura K, Mabuchi S, Yokoi T, Sasano T, Sawada K, Hamasaki T, et al. Utility of serum squamous cell carcinoma antigen levels at the time of recurrent cervical cancer diagnosis in determining the optimal treatment choice. Journal of gynecologic oncology. 2013, 24(4):321-329.

11. Hashimoto K, Yonemori K, Katsumata N, Hirakawa A, Hirata T, Yamamoto H, et al. Use of squamous cell carcinoma antigen as a biomarker of chemotherapy response in patients with metastatic cervical 
carcinoma. European journal of obstetrics, gynecology, and reproductive biology. 2011, 159(2):394398.

12. Gadducci A, Tana R, Cosio S, Genazzani AR. The serum assay of tumour markers in the prognostic evaluation, treatment monitoring and follow-up of patients with cervical cancer: a review of the literature. Critical reviews in oncology/hematology. 2008, 66(1):10-20.

13. Salvatici M, Achilarre MT, Sandri MT, Boveri S, Vanna Z, Landoni F. Squamous cell carcinoma antigen (SCC-Ag) during follow-up of cervical cancer patients: Role in the early diagnosis of recurrence. Gynecologic oncology. 2016, 142(1):115-119.

14. Sakuragi N. Up-to-date management of lymph node metastasis and the role of tailored lymphadenectomy in cervical cancer. International journal of clinical oncology. 2007, 12(3):165-175.

15. Takeshima N, Hirai Y, Katase K, Yano K, Yamauchi K, Hasumi K. The value of squamous cell carcinoma antigen as a predictor of nodal metastasis in cervical cancer. Gynecologic oncology. 1998, 68(3):263-266.

16. Lin H, ChangChien CC, Huang EY, Tseng CW, Eng HL, Huang CC. The role of pretreatment squamous cell carcinoma antigen in predicting nodal metastasis in early stage cervical cancer. Acta obstetricia et gynecologica Scandinavica. 2000, 79(2):140-144.

17. van de Lande J, Davelaar EM, von Mensdorff-Pouilly S, Water TJ, Berkhof J, van Baal WM, et al. SCCAg, lymph node metastases and sentinel node procedure in early stage squamous cell cervical cancer. Gynecologic oncology. 2009, 112(1):119-125.

18. Chang SJ, Kim WY, Yoo SC, Yoon JH, Chun M, Chang KH, et al. A validation study of new risk grouping criteria for postoperative treatment in stage IB cervical cancers without high-risk factors: rethinking the Gynecologic Oncology Group criteria. European journal of obstetrics, gynecology, and reproductive biology. 2009, 147(1):91-96.

19. Rogers L, Siu SS, Luesley D, Bryant A, Dickinson HO. Radiotherapy and chemoradiation after surgery for early cervical cancer. The Cochrane database of systematic reviews. 2012(5):CD007583.

20. Lee KB, Lee JM, Ki KD, Lee SK, Park CY, Ha SY. Comparison of adjuvant chemotherapy and radiation in patients with intermediate risk factors after radical surgery in FIGO stage IB-IIA cervical cancer. International journal of gynecological cancer : official journal of the International Gynecological Cancer Society. 2008, 18(5):1027-1031.

21. Ayhan A, Al RA, Baykal C, Demirtas E, Ayhan A, Yuce K. Prognostic factors in FIGO stage IB cervical cancer without lymph node metastasis and the role of adjuvant radiotherapy after radical hysterectomy. International journal of gynecological cancer : official journal of the International Gynecological Cancer Society. 2004, 14(2):286-292.

22. Ogino I, Nakayama H, Okamoto N, Kitamura T, Inoue T. The role of pretreatment squamous cell carcinoma antigen level in locally advanced squamous cell carcinoma of the uterine cervix treated by radiotherapy. International journal of gynecological cancer : official journal of the International Gynecological Cancer Society. 2006, 16(3):1094-1100. 
23. Kotowicz B, Fuksiewicz M, Jonska-Gmyrek J, Bidzinski M, Kowalska M. The assessment of the prognostic value of tumor markers and cytokines as SCCAg, CYFRA 21.1, IL-6, VEGF and STNF receptors in patients with squamous cell cervical cancer, particularly with early stage of the disease. Tumour biology : the journal of the International Society for Oncodevelopmental Biology and Medicine. 2016, 37(1):1271-1278.

\section{Figures}

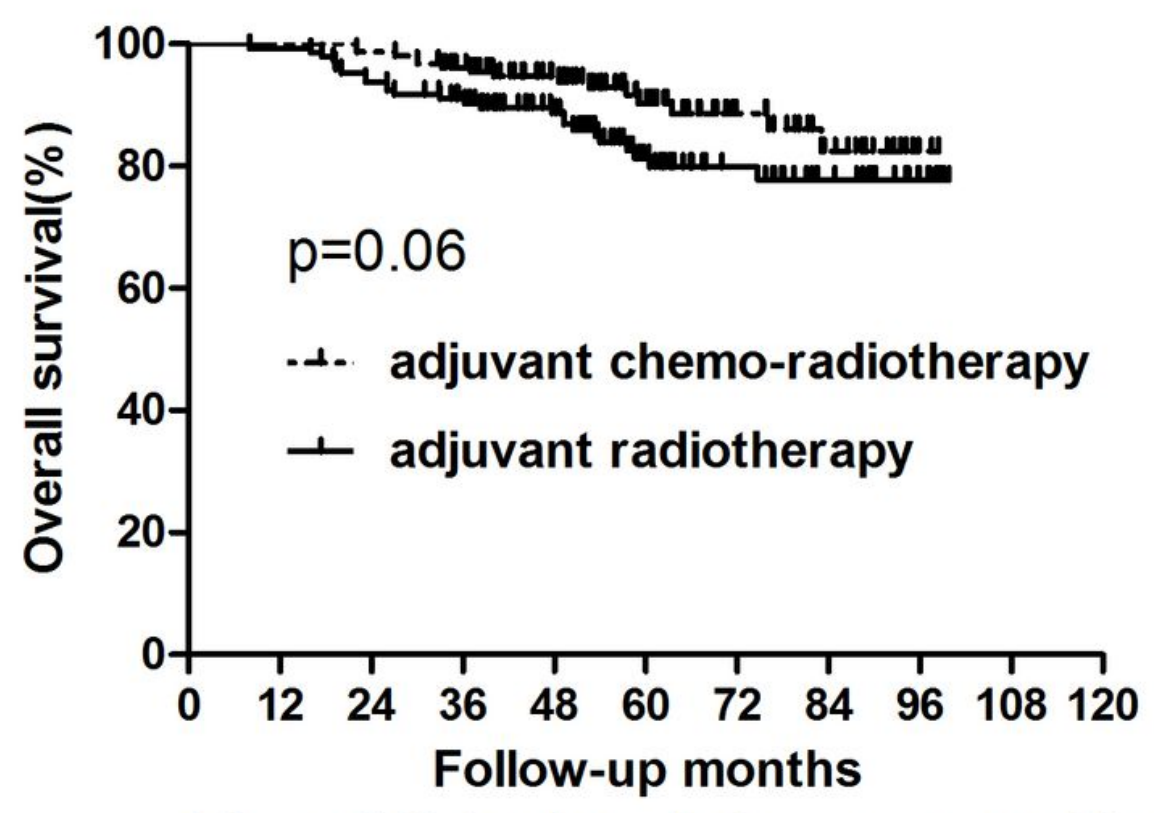

Fig 1. OS for the whole group stratified by adjuvant chemotherapy

Figure 1

Overall survival for the whole group of patients. No significant difference was found in overall survival between patients who did and did not receive concurrent chemotherapy $(p=0.060)$. 


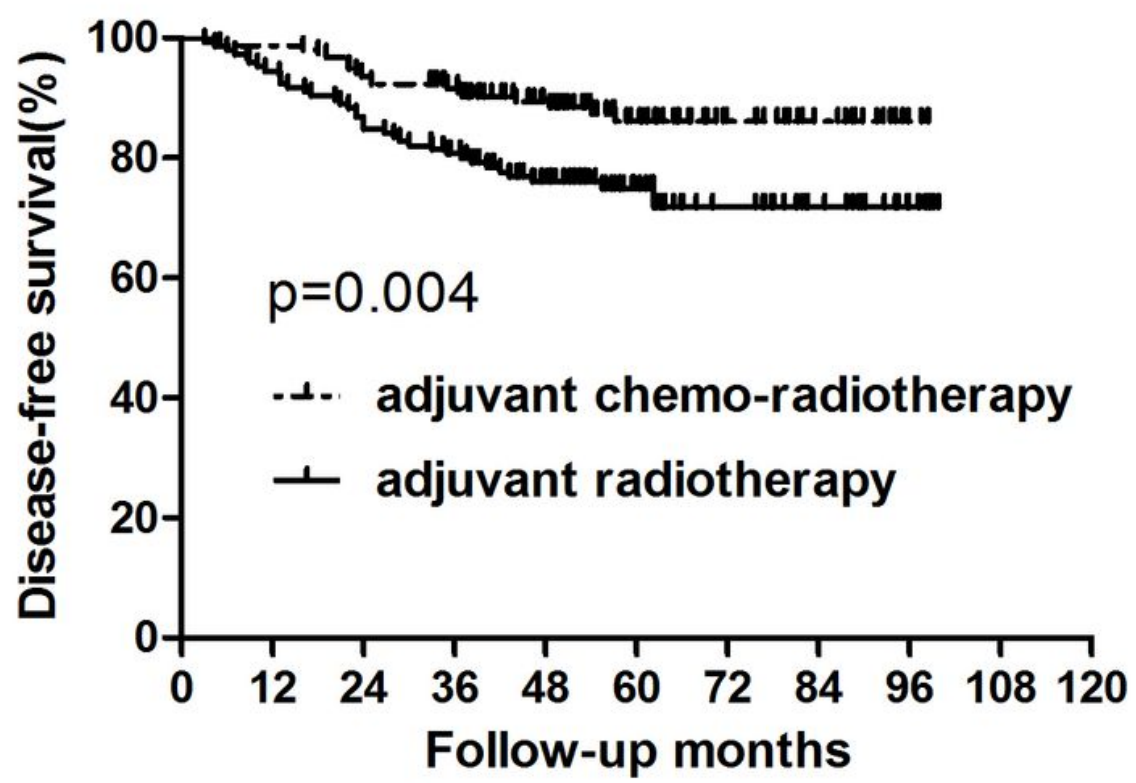

Fig 2. DFS for the whole group stratified by adjuvant chemoherapy

Figure 2

Disease-free survival for the whole group of patients. Significant difference was found in disease-free survival between patients who did and did not receive concurrent chemotherapy $(p=0.004)$.

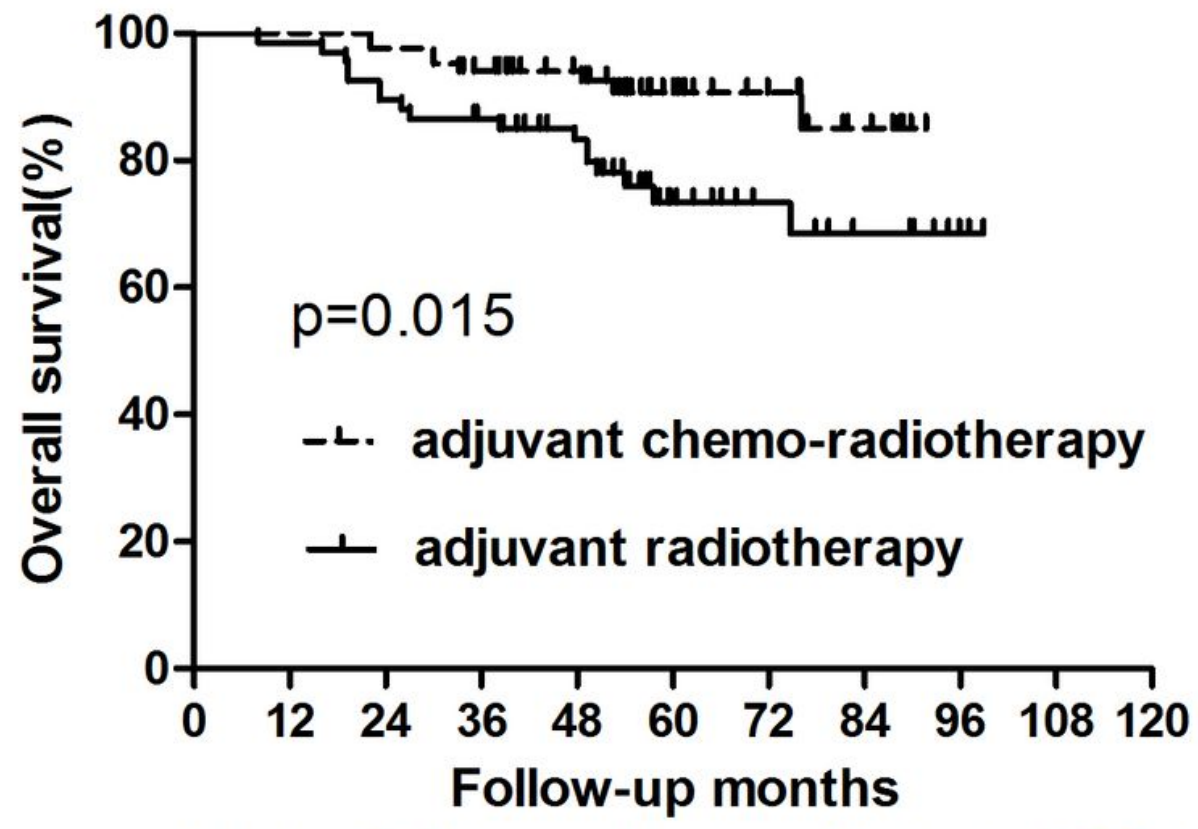

Fig 3. OS for patients with high SCC level stratified by adjuvant chemotherapy

Figure 3 
Overall survival for the subgroup of patients with high squamous cell carcinoma level. Significant difference was found in overall survival between patients who did and did not receive concurrent chemotherapy $(p=0.015)$.

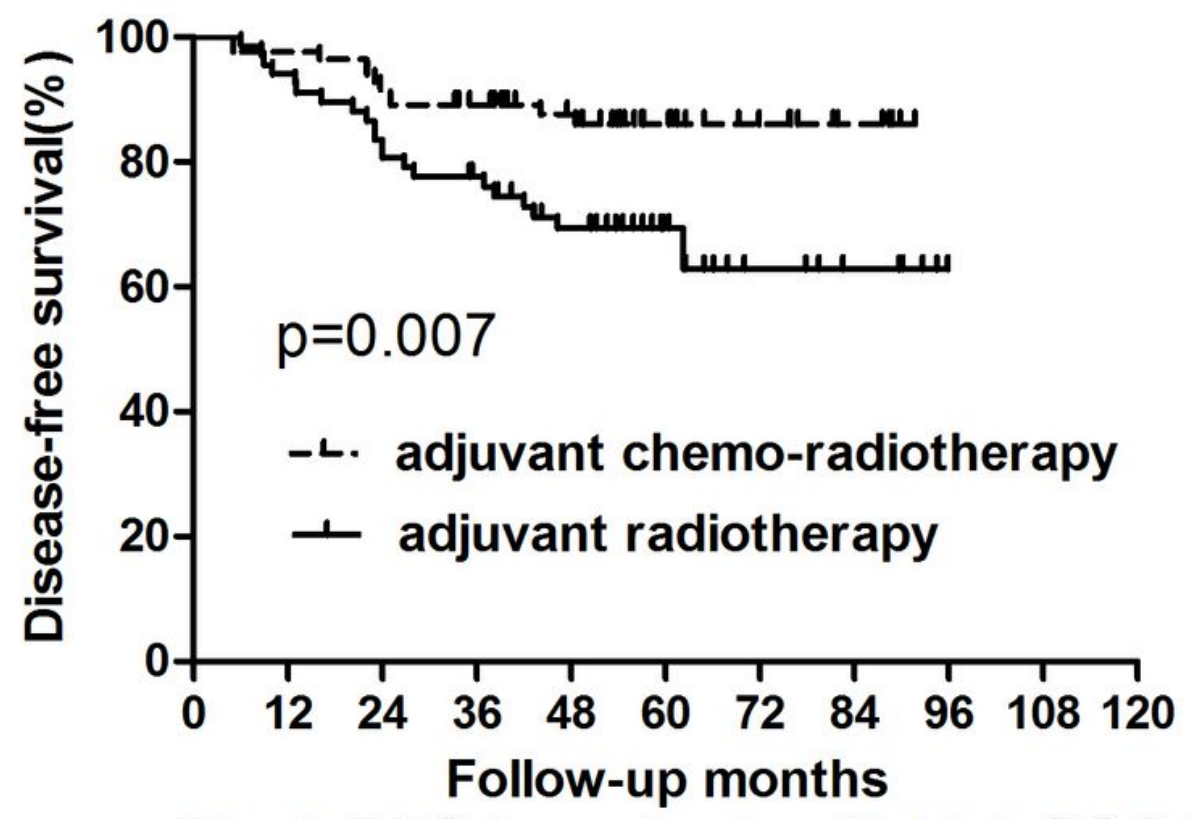

Fig 4. DFS for patients with high SCC level stratified by adjuvant chemotherapy

Figure 4

Disease-free survival for the subgroup of patients with high squamous cell carcinoma level. Significant difference was found in disease-free survival between patients who did and did not receive concurrent chemotherapy $(p=0.007)$. 


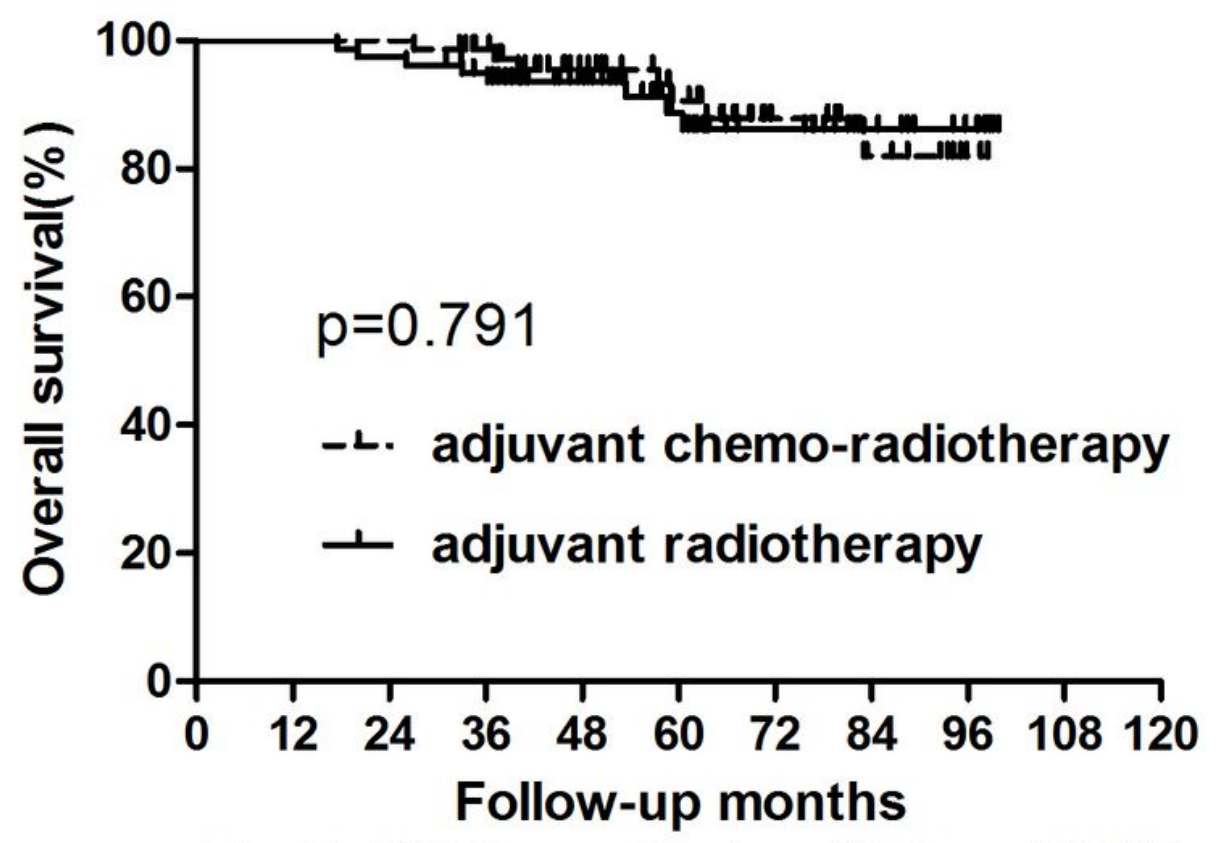

Fig 5. OS for patients with low SCC level stratified by adjuvant chemotherapy

Figure 5

Overall survival for the subgroup of patients with low squamous cell carcinoma level. No significant difference was found in overall survival between patients who did and did not receive concurrent chemotherapy $(p=0.791)$.

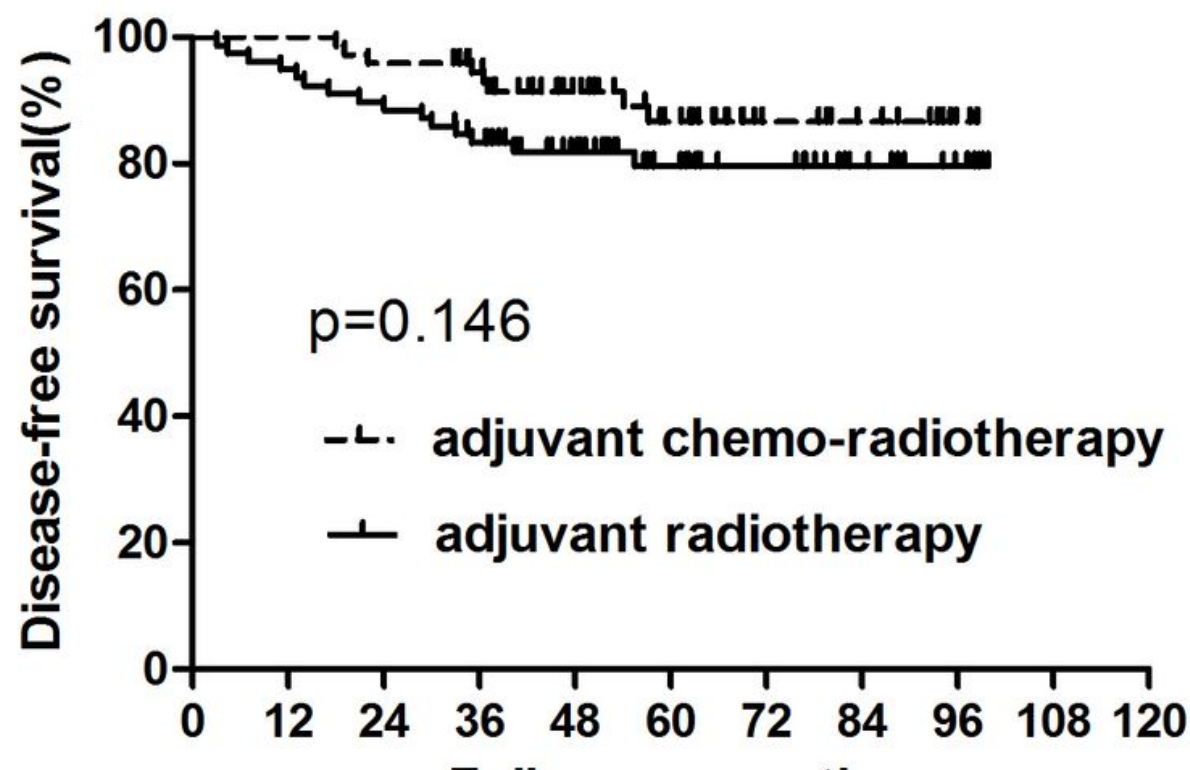

Follow-up months

Fig 6. DFS for patients with low SCC level stratified by adjuvant chemotherapy 
Figure 6

Disease-free survival for the subgroup of patients with low squamous cell carcinoma level. No significant difference was found in disease-free survival between patients who did and did not receive concurrent chemotherapy $(p=0.146)$. 